\title{
Study of Abrasive Cutting of Natural Quartz for Manufacturing Piezoelectric Power Generators
}

\author{
L.A.O. Araujo ${ }^{1, a}$, J.M.D.A. Rollo ${ }^{2, b}$, C.R. Foschini ${ }^{3, c}$, C.A. Fortulan ${ }^{1, d}$ \\ ${ }^{1}$ University of Sao Paulo, School of Engineering from Sao Carlos. Mechanical Eng. Department, \\ Laboratory of Tribology and Composites. Av. Trabalhador Sao Carlense, 400. City: Sao Carlos, \\ State: Sao Paulo. Country: Brazil. ZIP CODE 13566-590 \\ ${ }^{2}$ University of Sao Paulo, School of Engineering from Sao Carlos, Material Eng. Department. Av. \\ Trabalhador Sao Carlense, 400. City: Sao Carlos, State: Sao Paulo. Country: Brazil. ZIP CODE \\ 13566-590
}

${ }^{3}$ UNESP - Universidade Estadual Paulista Julio de Mesquita Filho, School of Engineering, Department of Mechanical Engineering. Av. Engenheiro Luiz Edmundo Coube, 1401. City: Bauru. State: Sao Paulo. Country: Brazil. ZIP CODE: 17033-360

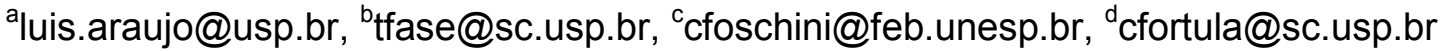

Keywords: abrasive cut, dicing saw, band saw, energy harvesting quartz.

\begin{abstract}
The present study is related with the dicing of natural quartz crystals as part of the process manufacturing of a power generator device. Power generation is important, mainly for wifi systems, which use of batteries is restrictive or impossible due short dimensions and difficult of maintenance. The manufacturing dicing process applied in micro electromechanical systems (MEMS) is the main reference for this study, which objective is explores different parameters of dicing process and the impact of it in the final performance of the generator. Failure impregnation and productivity were study in blade and band saw process with different parameters as speed and cutting force. The natural quartz was selected mainly because availability in Brazil and piezoelectric properties. It was obtained substrates AT cutting plan with thickness of $2.5 \mathrm{~mm}$ and width of $3 \mathrm{~mm}$. The material was tested under compressive stress and the correspondent electric signal was obtained.
\end{abstract}

\section{Introduction}

Currently, it is well known, there are several efforts in the development of renewable energy sources. The electricity is one of the key features that have been receiving more attention from governments, research institutions and industries [1,2]. In this study, the focus is related with a renewable electric low power generator, using mechanical stress of piezoelectric material to generate energy. This kind of piece can be applied in embedded systems, autonomous or not, complementing or even replacing the batteries. Usually, it can be called as Energy Harvesting Power Generator [5].

The objective of this examination is to evaluate some abrasive dicing processes that can be applied in the manufacturing of energy harvesting power generators based on natural quartz single crystals. It's also part of the study, analyze the impact of failures generated in the abrasive process and the functional of the power generator.

\section{Materials and Methods}

The natural quartz single crystal was selected mainly due availability in Brazil and its piezoelectric properties. The quartz has also considerable stability in crystal structure (changing from $\alpha$-quartz to $\beta$-quartz in $573^{\circ} \mathrm{C}$ ), low thermic expansion $\left(1.75 \times 10^{-6} \mathrm{~K}^{-1}\right.$ in $20^{\circ} \mathrm{C}$ ), high fusion temperature (over $1670^{\circ} \mathrm{C}$ ), high Young Modulus (from 78.3 to $127.6 \mathrm{GPa}$, according with cutting plan), etc. The natural quartz had application as crystal oscillator to radio technology and also as broadcast radio frequency controllers. However, it suffers due to inclusion of impurities, bubbles, 
cracks and twinning, which reduce performance and repeatability during process manufacturing and use. Currently, the natural quartz has a massive application as seeds for the growing process of synthetic quartz, which generate crystals with reduced number of defects and better performance in applications [3].

Temperature and pressure can change the phase of the material; because of this it were adopted Thermal Expansion Curves and Low Dicing Forces as main quality controls parameters. The process of slicing a primitive rock of quartz in a specific cutting plan was made in a heavy duty dicing machine and also in a band saw EXAKT 300 (abrasive belt Ref. 34320 EXAKT). Cutting plan inspection uses an X-ray diffractometer XRD 7000 - SHIMADZU. The slice was diced to a parallelepiped shape by a dicing saw DISCO DAD 3350, using abrasive blade THERMOCARBON (model / code: 2.25M-10C-54R7-3, 2" diameter, 0,254 mm thickness and $54 \mu \mathrm{m}$ grain sizes). After shape the material, two opposite faces received electrodes in silver (Ag) TICON 4080. Inspection plan focus in measure the electric voltage under different stress over the parallelepiped.

The method to develop this study includes the characterization of some micro electric mechanic components / systems samples available in market with similar process manufacturing (abrasive process manufacturing). This is the reference for permissible or not permissible surface finishing and chipping edge.

The sequence of operations is organized in a frame represented by Fig. 1.

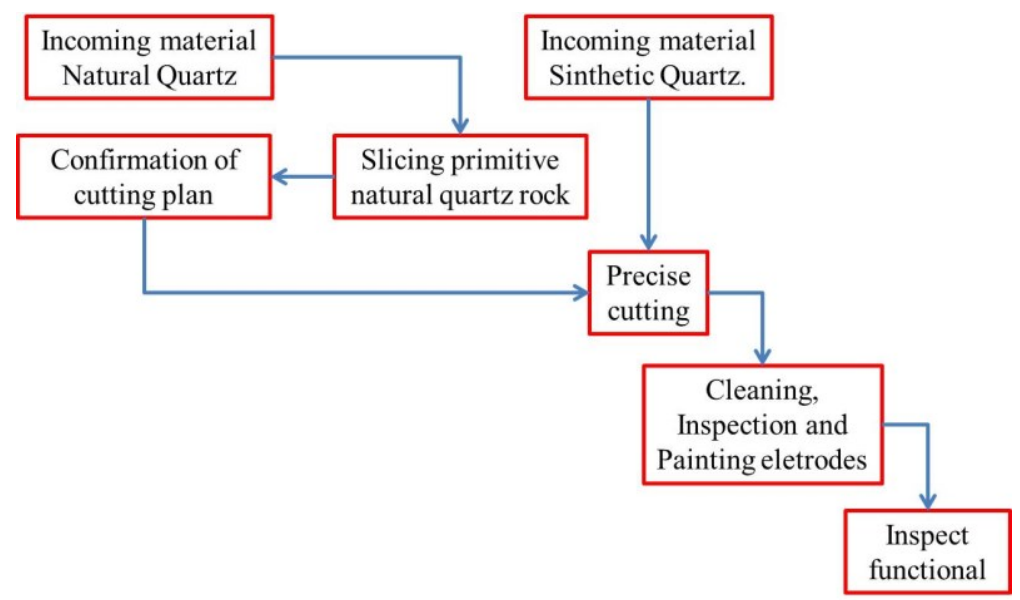

Fig. 1. Sequence of operations to develop a quartz energy harvest generator.

\section{Results}

Two components made in quartz were analyzed: mass balance sensor and a tuning fork (Fig. 2).

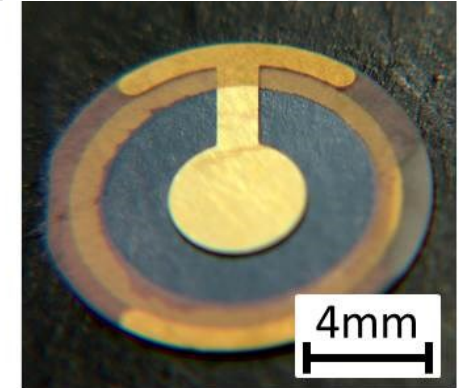

a)

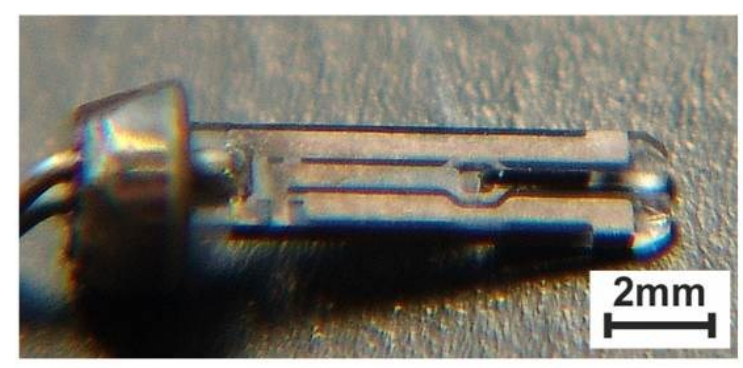

b)

Fig. 2. Components analyzed, in a) Mass Balance Sensor, in b) Quartz Tuning Fork.

In the case of quartz mass balance sensor (QMB), the surface and edge finishing were investigated in different areas (Fig. 3). A SEM (Scanning Electron Microscopy) indicates dissimilar finishing according with the area location. 


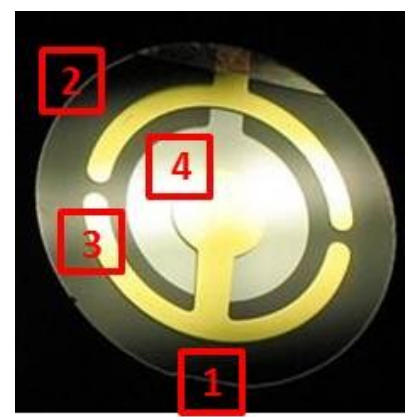

Fig. 3. Schematic of analyzed area location over QMB.

The qualitative study (imagens) is presented in Fig. 4.

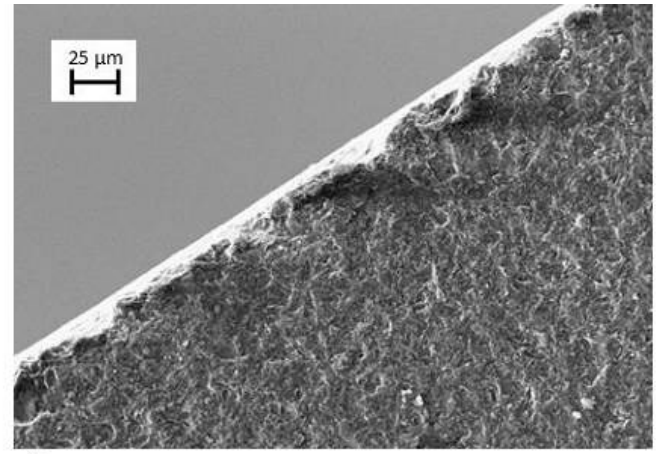

a)

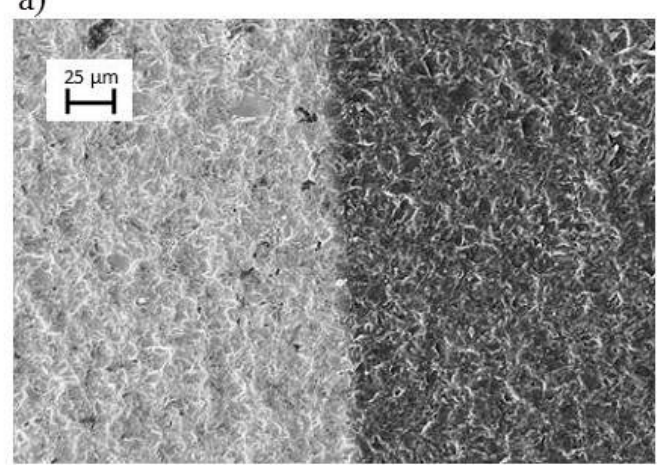

c)

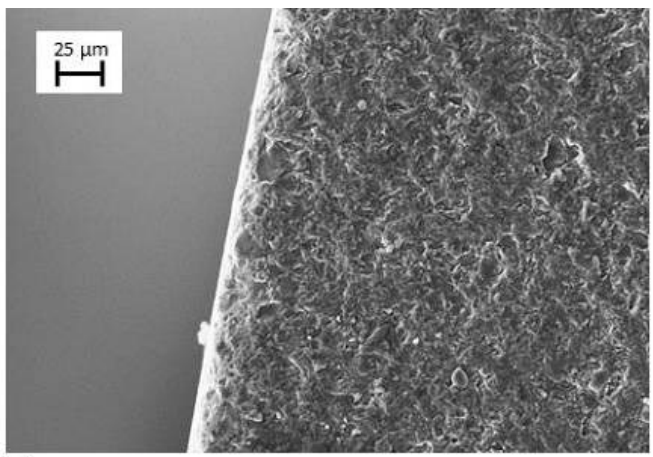

b)

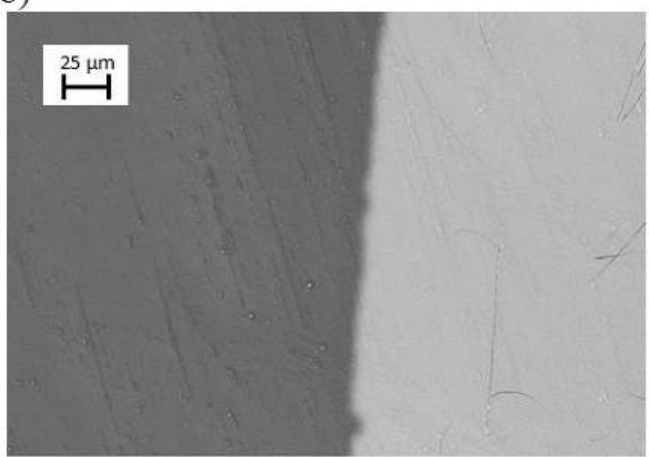

d)

Fig. 4. Areas from QMB. In a) area 1, in b) area 2, in c) area 3 and in d) area 4.

From areas 1 to 4 , roughness decrease visually, demonstrating it's possible to have different range of acceptable surface finishing that don't have influence in the functional of the QMB. The process of remove material from a hard and brittle material as silicon or a ceramics can impregnate the specimen with many defects, as cracks, chipping, roughness, etc. $[4,5,6]$.

The quantification of the roughness was made by the profiler system Veeco, Wyco NT110. It pointed values of average roughness ( $\mathrm{Ra}$ ) from around $1.0 \mu \mathrm{m}$ to $0.25 \mu \mathrm{m}$ (from areas 1,2 and 3 to area 4). Maximum height of the profile (Rt) from around $11 \mu \mathrm{m}$ to $2.5 \mu \mathrm{m}$ (from areas 1,2 and 3 to area 4). Thickness was smaller at periphery (areas 1 and 2) and bigger at the center areas (3 and 4).

The tuning fork had a homogenous roughness and a reduced number of chipping in the edges.

During this work, several types of quartz were analyzed and machined in different process for comparison. The natural quartz had great emphasis due the procedures of finding cutting plane and the use of a heavy duty dicing saw with metal blade to slice the primitive quartz rock (Fig. 5). The AT cutting plan was the target. It was developed a support with the angle of $35^{\circ} 15^{\prime}$ (characteristic of AT cutting plan) and after cutting, each slice was grinded and polished. 


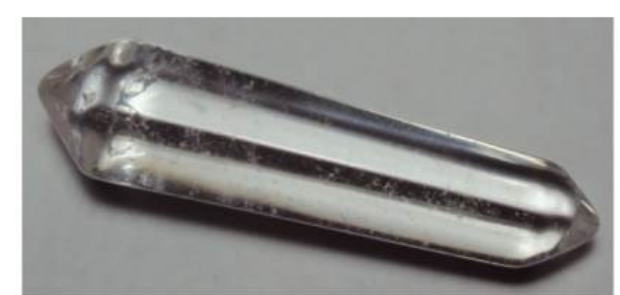

a)

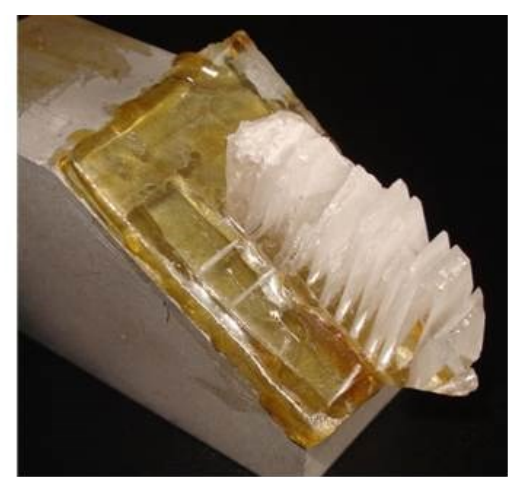

b)

Fig. 5. In a) a primitive quartz rock $40 \mathrm{~mm}$ length. In b) the sample sliced in AT cutting plan.

The idea was reduce the roughness and chipping in the edge of the specimen, reducing the potential generation of tension and cracking propagation during stress functional. An optional process was also applied with good results, eliminating the grinding and polishing process after slicing, it was the band saw process. In this case, there was just one inconvenient; the slicing process became too slow in more than 100 times than the heavy duty dicing saw (Fig. 6).

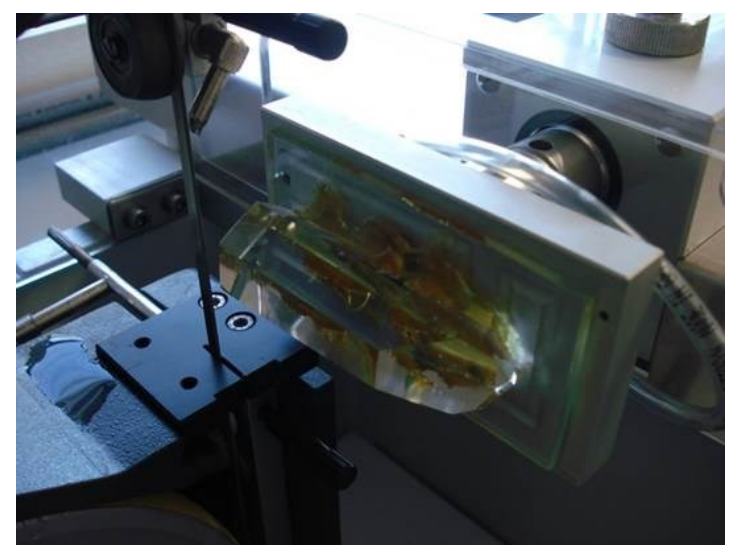

Fig. 6. Band saw process.

The profile roughness $\mathrm{Ra}$ was around $450 \mathrm{~nm}$ for $5 \mathrm{~mm} / \mathrm{s}$ of feed speed belt and Rt around $17.6 \mu \mathrm{m}$ (Fig. 7). Higher values of feed speed increase roughness (Ra and Rt) and number of cracks.

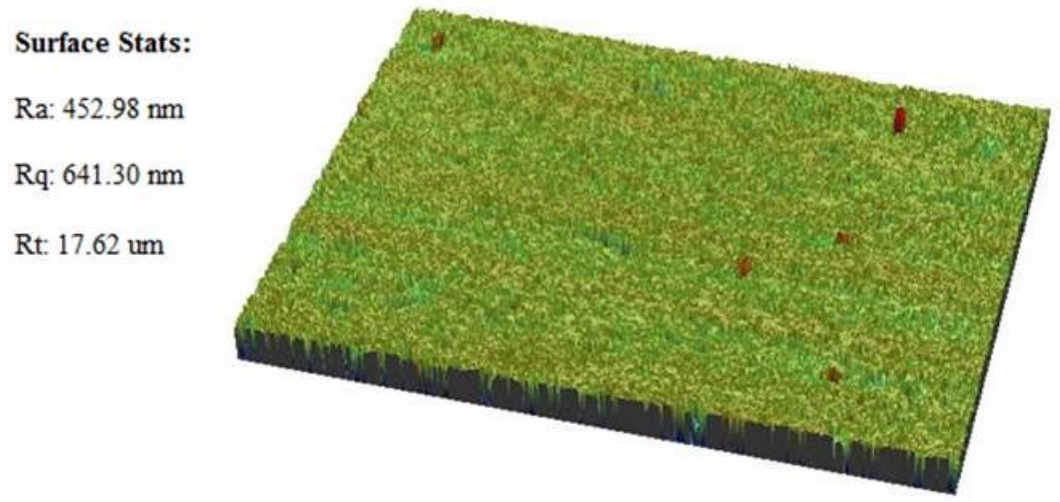

Fig. 7. Profile surface from a band saw process feed speed $5 \mathrm{~mm} / \mathrm{s}$.

The precise cutting was made with abrasive blade from THERMOCARBON, with $30.000 \mathrm{rpm}$ and feed speed of $1 \mathrm{~mm} / \mathrm{s}$. Final dimensions $3.0 \times 3.0 \times 2.5 \mathrm{~mm}$. A certain number of chips were found after precise cutting, but as pointed in the qualitative and quantitative study of the QMB, defects can be acceptable, but of course, it's necessary to define the dimension of the acceptable. Figure 8 is a qualitative view of the chipping in the edges of the specimen after precise cutting. 


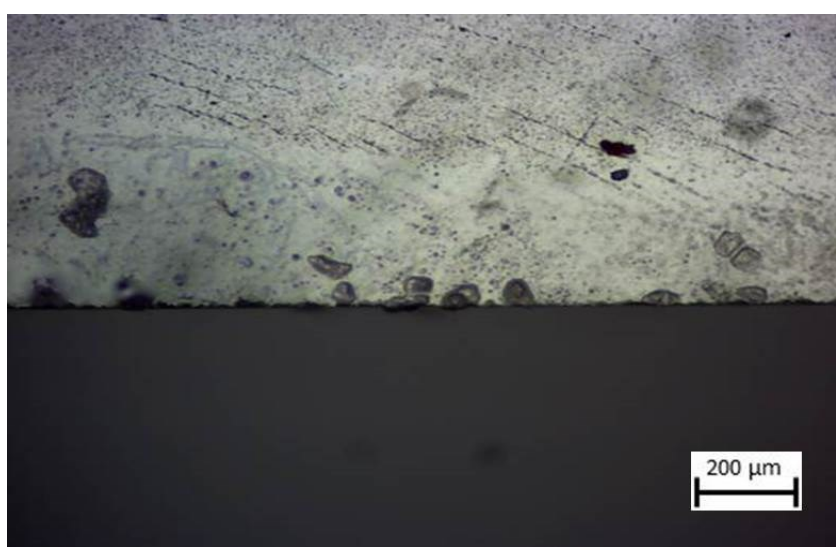

Fig. 8. Edge of quartz after precise cutting.

The electrodes were constructed in silver (Ag) TICON 4080 that is liquid at $25^{\circ} \mathrm{C}$. According with supplier, it metalizes after $550^{\circ} \mathrm{C}$ during $40 \mathrm{~min}$. The temperature of changing phase $\alpha-\beta$, is around $573{ }^{\circ} \mathrm{C}$ (expected). The samples of quartz were tested in a dilatometry (Fig. 9), confirming the right temperature of change phase for each natural quartz sample.

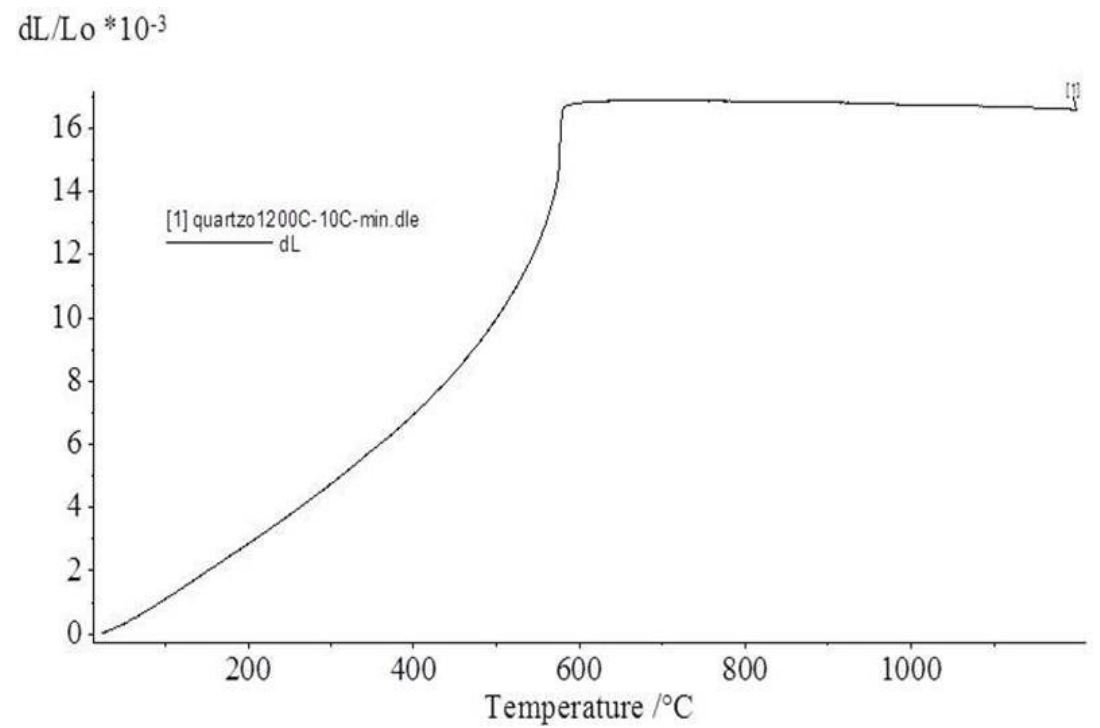

Fig. 9. Dilatometry of natural quartz.

After the metallization of silver (Ag) electrodes, the piece was tested consisted in a simple impact producing peaks of voltage in around $500 \mathrm{mV}$. The final piece is presented at Fig. 10 .

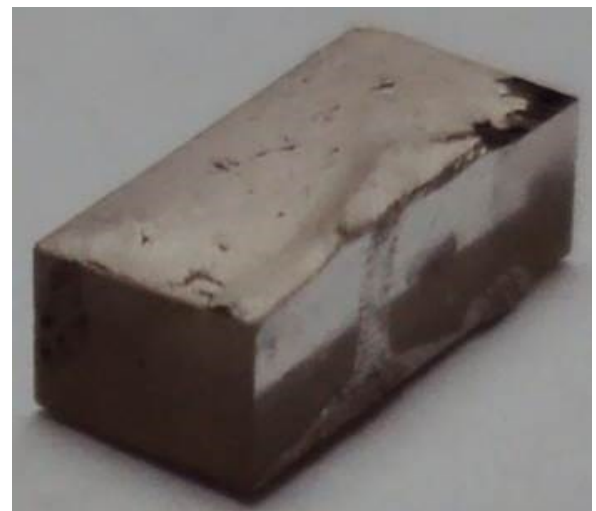

Fig. 10. Final piece of natural quartz, cutting plan AT and electrodes in Ag. 


\section{Conclusions}

According with the design of the QMB, it's became clear that the type of stress applied in the crystal will define the quality of surface finishing. In the case of the crystal generator produced in this study, the stressed applied (impact), demonstrated not so important for one or two impacts. Alternatively it's necessary to submit the specimen to a complete fatigue tests, finding the number of cycles it will have functional.

The Tuning Fork works in high frequency, more than $100 \mathrm{KHz}$, what suggest a better surface finishing.

The abrasive process indicates as much aggressive it is, defects will be impregnated proportionally in the diced piece.

The band saw process demonstrates higher benefits in Ra in comparison with a heavy duty dicing process with metal blade. It also confirm, as much aggressive the cutting parameters were, more failures will be intake to the diced material.

\section{References}

[1] F.C. Camioto, O uso de fontes limpas de energia na indústria paulista: um estudo envolvendo a técnica do incidente crítico e a análise conjunta. Mestrado (Dissertação). São Carlos, 2010. Universidade Federal de São Carlos (UFSCar). SP.

[2] R. Kuehr: Journal of Cleaner Production (2000).

[3] A. L. Kholkin, N.A. Pertsev, A.V. Goltsev, Piezoelectricity and Crystal Symmetry. In: Piezoelectric and Acoustic Materials for Transducer Applications, Safari A. Akdoğan E.K. Ed. Springer, 2008, p. 17.

[4] H. Fujita et al.:Cerâmica Vol. 52 (2006), p. 269.

[5] E.L. Nix, et al. Dicing and grinding of electroceramics. CARTS Europe (2005).

[6] S.Y. Luo, Z.W. Wang: The International Journal of Advanced Manufacturing Technology Vol. 35 (11-12) (2008), p. 1206.

[7] L.A.O. Araujo: Projeto conceitual e construção de um protótipo de uma minimáquina para o corte de substratos de Alumina. Mestrado (Dissertação). São Carlos, 2009. Universidade Federal de São Carlos (UFSCar). SP.

[8] C.S. McGahey: Harnessing Nature's Timekeeper: A History of the Piezoelectric Quartz Crystal Technological Community (1880-1959), Dissertation (PhD in School of History, Technology and Society) - Georgia Institute of Technology (2009). 
Reproduced with permission of copyright owner. Further reproduction prohibited without permission. 